\title{
XI. Transformations of X-rays
}

\section{Charles A. Sadler M.Sc.}

To cite this article: Charles A. Sadler M.Sc. (1909) XI. Transformations of X-rays, Philosophical Magazine Series 6, 18:103, 107-132, DOI: $10.1080 / 14786440708636676$

To link to this article: http://dx.doi.org/10.1080/14786440708636676

册 Published online: 21 Apr 2009.

Submit your article to this journal $\pi$

Џll Article views: 3

Q View related articles $\asymp$

4 Citing articles: 8 View citing articles 
If we take the amount of radium in sea-water as $10^{-15}$ gram per gram of water, and in the soil as $4 \times 10^{-12}$, a simple calculation * shows that the penetrating radiation from the soil should be about 1600 times as great as from the ocean, so far as the penetrating radiation may be attributed to the presence of radium.

If we follow a calculation of Becker $\dagger$, we find the radium contents of the ocean to be equivalent to the radium found in a very small thickness of the deposits at the bottom of the ocean. Let us suppose the ocean contains $9 \times 10^{-15}$, the deep-sea deposits $25 \times 10^{-12}$ (Joly), and the sedimentary rocks $1 \cdot 1 \times 10^{-12}$ (Strutt), in each case in terms of grams of radium per gram of material. Take the mean depth of the ocean as 3.5 kilometres and the specific gravity of the deposit or soil as 2.5 . Then the amount of radium in $3.5 \mathrm{~km}$. depth of ocean, per sq. cm., is about equal to that, also per sq. cm, in 114 cms. of sedimentary rock, or 5 cms. of deep-sea deposit.

\section{Summary.}

1. Radium emanation may be collected over water or over mercury with about equal accuracy when testing for the quantity present in a given solution.

2. The result of testing six samples of sea-water from the North Atlantic leads to the average value of $9 \times 10^{-16}$ grau of radium per gram of sea-water. This is about one-seventeenth of the value found by Joly.

Montreal, A pril 1909.

XI. Transformations of X-Rays. By Cha Rles A. SAdLer, M.Sc., Oliver Lodge Fellow, University of Liverpool †.

$\mathrm{W}^{\mathrm{s}}$ HEN a primary beam of Röntgen radiation falls upon any substance, secondary Röntgen rays are emitted, the character of which depends both upon the nature of the substance and upon the particular kind of primary beam used. With reference to the latter it has been found that variations in the intensity of the primary beam produce no perceptible change in the character of the resulting secondary, the sole controlling factor appearing to be the degree of " hardness" of the primary $\$$.

* 'Terrestrial Magnetism,' March 1909.

+ Bull. Geol. Soc. of America, vol. xix. p 113 (1908).

+ Communicated by the Physical Society : read A pril 23, 1909.

$\$$ Barkla, Phil. Mag. June 1906, pp. 812-828. 
It has been shown ${ }^{*}$ that if the radiating substance be an element of lcw atomic weight-as hydrogen, oxygen, or carbon-it emits a radiation similar in penetrating power to the primary producing it; its penetrating powor varying with that of the producing primary. This type of radiation, which will be referred to as a "scattered" radiation, may be considered as proluced by an acceleration of one or more electrons in the atom of the radiating substance, due to the action of forces in the primary pulse.

From an element of greater atomic weight than that of calcium (40)-and possibly from orher elements of lower atomic weight ander very penetrating primary beams-the emitted radiation has been shown to consist of scattered radiation, and superposed upon this, a type of radiation which is characteristic of the radiating element. The penetrating power of this radiation is a constant quantity peculiar to the substance and is independent of the penetrating power of the primary producing it. Moreover, this radiation appears to be entirely homogeneous in character, and experiments point to the conclusion that the radiating electrons producing this type of radiation are no longer appreciably under the influence of the forces in the primary pulse.

This homogeneous radiation is only produced when the penetrating power of the primary is greater than that of the homogeneous radiation characteristic of the radiator.

From the group of elements $\mathrm{Cr}-\mathrm{Ag}$ the ionization produced by the homogeneous portion of the secondary radiation, emitted when any of its members is subjected to a sufficiently penetrating primary, is many times greater than that produced by the scattered portion-in the case of copper as radiator this ratio is as high as $150: 1$.

The homogeneous radiation from chromium is very "sof $t$ " much softer indeed than any ordinary primary beam, and from chromium down to silver and probably beyond, the penetrating power of the characieristic radiation increases with increase of atomic weight; the radiation from silver being many times more penetrating than that from chromium.

One of the chief difficulties experienced in the investigation of X-ray phenomena has been the heterogeneity of the primary beams hitherto available. Even where devices are adopted to ensure that the current through the X-ray bulb used as a source of primary rays is uni-directional and of nearly constant strength, the primary so obtained consists of a mixture of constituents of different penetrating power; so

* Barkla \& Sadler, Phil, Mag. Oct. 1908 pp. 550-584. 
there remains the difficulty of ascertaining which particular constituents of the composite beam are principally concerned in producing the phenomena under investigation.

It was thought that useful information concerning the nature of X-rays might be obtained if the homogeneous rays previously mentioned were used to excite tertiary radiation in different substances.

Sagnac has shown that the tertiary $\mathrm{X}$-rays from metals exited by secondary $X$-rays are more easily absorbed than the exciting rays.

Previous experiments * had shown that if two substances $A$ and $B$ be taken, each of which is found to emit a homogeneous radiation when a suitable primary beam falls upon it, the homogeneous radiation from $A$ being more penetrating than that from $B$, then if a homogeneous beam from $A$ be passed through a thin plate of $B$, tertiary radiation is excited in $B$ by the radiation from $A$, while if the process is reversed it is found that the radiation from $B$ excites no tertiary radiation in A.

These phenomena were examined in greater detail in the experiments described below.

It was found that no trace of a homogeneous tertiary radiation could be detected from aluminium when subjected to any of the homogeneous radiations from the group of metals $\mathrm{Cr}-\mathrm{Ag}$, and the amount of scattered radiation produced was extremely small when compared with the secondary incident beam.

Advantage was taken of these facts, and the.primary and secondary beams were passed through tubes of thick aluminium of rectangular cross-section. This enabled the apparatus to be arranged compactly with comparatively sbort distances between the anticathode of the X-ray bulb and the secondary radiator, and between the secondary and tertiary radiators respectively, a condition essential to secure that the ionization produced by the tertiary rays in a suitable ionization chamber should be sufficiently intense to ensure accurate readings in a reasonably short time, and that the direct tertiary radiation should produce an ionization large compared with that produced by stray secondary and tertiary rays from the surrounding air and neighbouring screens.

The general arrangement of the apparatus is indicated in Plan by fig. 1 .

A rectangular brass tube $B$ lined with aluminium $\cdot 2 \mathrm{~cm}$. thick was fitted into an aperture in the lead screen SS surrounding the X-ray bulh emitting the primary rays, and the

* Rarkla \& Sadler, Phil. Mag̣. Oct. 1908, pp. 550-584. 
bulb was so placed relatively to this tube that the axis of the tube passed through the centre of the anticatbode A normally.

Fig. 1.

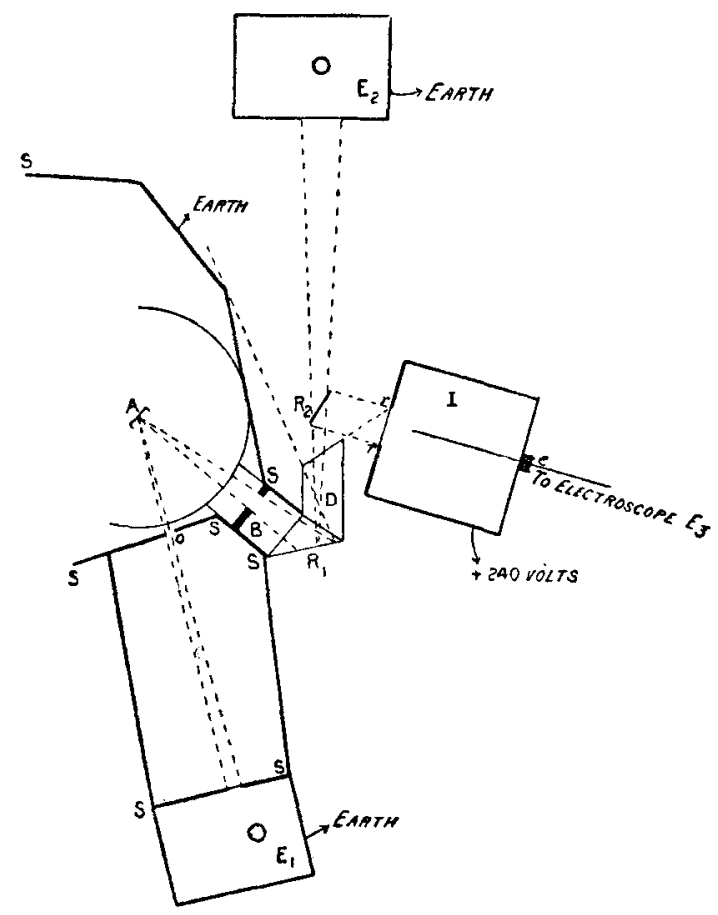

The rays from $\Lambda$ passing through this tube impinged on the radiator $R_{1}$ consisting of a rectangular plate of the metal, the secondary rays from which were to be studied. A portion of the secondary rays so produced passed down the rectangular brass tube $D$ lined as before with $\cdot 2 \mathrm{~cm}$. aluminium, and a plate of any substance placed in this secondary beam provided a source of tertiary rays.

The intensity of the primary beam was measured by allowing a narrow pencil of rays proceeding from $\mathrm{A}$ through a small aperture $\mathrm{O}$ in the lead screen SS to enter an electroscope $\mathrm{E}_{1}$ of the ordinary Wilson type through an opening covered with tissue-paper and aluminium-foil in the wall of the electroscope.

The deflexions of the gold. leaf were observed by means of a microscope fitted with a scale in the eyepiece.

The intensity of the secondary beam was measured by means 
of a similar electroscope $E_{2}$ placed in the path of the secondary beam passing down the tube $D\left(R_{2}\right.$ removed) as indicated in the Plan ; the size of the aperture in the wall of this electroscope being $3 \times 2$ cms.

It was fonnd that by carefully shielding the electroscopes $\mathrm{E}_{1}$ and $\mathrm{E}_{2}$ from draughts and sudden changes of temperature very reliable readings could be obtained, the motion of the gold-leaf being absolutely dead-beat.

Preliminary experiments also showed that with a given radiator $R_{1}$ in position ( $R_{2}$ being removed) the ratio of the deflexions in $E_{1}$ and $E_{2}$ when the bulb had reached a steady state rarely varied by more than 1 per cent. during a series of readings.

The ordinary Wilson type of electroseope was found to be quite unsuitable as a means of measuring the tertiary radiation; the type of electroscope described by R. T. Beatty in his paper on "Secondary Röntgen Radiation in Air" * was finally adopted. Briefly described, this consisted of a brass case having two sliding quadrants insulated from the case and charged to potentials of +240 and -240 volts respectively ; an insulated gold-leaf hung vertically between them and was connected to the wire $e$, which projected into and was insulated from the ionization-chamber $\mathrm{I}$, which itself was insulated and charged to +240 volts. In adjustable compensating-chamber insulated and charged to -240 volts eliminated the normal ionization in the chamber $I$. The sensitiveness of the electroscope was adjustable by means of the sliding quadrants.

With the order of sensitiveness required iu all the experiments described, the motion of the gold-leaf was dead-beat, and a series of readings of the ratio of deflexions in electroscopes $E_{1}$ and $E_{2}$ showed that with deflexions up to 20 scaledivisions in $\mathrm{E}_{2}$ this could be obtained with an accuracy of 2 per cent. with certainty.

A calibration of electroscopes $\mathrm{E}_{1}$ and $\mathrm{E}_{2}$ showed that the value of a deflexion of a scale-division was the same within 1 per cent. throughout the range of scale employed.

The sensitiveness of $\mathrm{E}_{3}$ was adjusted and then maintained constant throughout a given series of readings, and in all readings a constant deflexion of $\mathrm{E}_{3}$ was used, thus eliminating the effect of the slight change in value of a scale-division which was found to exist in different parts of the scale.

Preliminary experiments showed that the secondary radiation from air together with other stray effects were very

* R. T. Beatty, Phil. Mag. Nov, 1907, pp. 604-614. 
small compared with the readings obtained when metallic radiators were employed.

The portion of the radiator $R_{1}$ exposed to the primary beam was limited to that opposite to the tube $\mathrm{D}$ by means of a suitable stop placed in the tube $B$ as indicated in the diagram.

\section{Nature of the Tertiary Rays.}

It was perhaps reasonable to expect that the tertiary radiation emitted by any member of the group $\mathrm{Cr}-\mathrm{Ag}$ when subjected to a more penetrating homogeneous beam from the same group would be identical in character with that emitted as secondary radiation by the same substance when excited by a suitable primary.

Direct experiments were carried out to test how far this was true, and for this purpose pure iron was chosen as the tertiary radiator.

The radiator consisted of a small rectangle $3 \mathrm{cms}$. high by $2 \mathrm{cms}$. broad, formed of pure iron wire interlaced so as to expose as large a surface as possible to the exciting beam. This was placed in the position indicated by $R_{2}$, the centre of the radiator was at the intersection of the axis of the tube $D$ with the normal from the centre of the aperture to the ionization-chamber I, the plane of the radiator making equal angles with these directions.

As a secondary radiator in the position $R_{1}$ a plate of pure copper was used.

The aperture YY of the ionization-chamber $I$ in these experiments was $3 \mathrm{cms}$. high by $2 \mathrm{cms}$. broad, and the distance from the centre of the aperture to the centre of $\mathrm{R}_{2}, 4$ cms.

Owing to the obliquity of some of the tertiary rays, it was evident that the absorption coefficients, obtained by studying the absorption by thin plates of different substances placed parallel to the aperture YY in the path of the beam, would be greater than would have been the case had it been possible to utilize a pencil of tertiary rays.

A control experiment conducted with a fairly soft primary beam falling upon the same iron radiutor similarly situated before an aperture of the same size as that in the screen $\mathrm{YY}$ in an electroscope of the Wilson type placed in the secondary beam from the iron, gave an increase in the value of the absorption coefficient by an aluminium plate $.00297 \mathrm{~cm}$. thick of 6 per cent. over the value found when a narrow pencil of secondary radiation was used. 
The absorption coefficients of the tertiary bean from iron were then determined by thin sheets of aluminium, iron, copper, and zinc. The values so obtained are compared with those obtained when the same absorbers were used with the secondary rays in the control experiment in the following table.

\section{TABLE I.}

\begin{tabular}{|c|c|c|}
\hline Absorber. & $\begin{array}{l}\text { Value of } \frac{\lambda}{\rho} \text { for } \\
\text { Secondary Rays. }\end{array}$ & $\begin{array}{l}\text { Value of } \frac{\lambda}{\rho} \text { for } \\
\text { Tertiary Rays. }\end{array}$ \\
\hline $\mathrm{Al}(00297 \mathrm{~cm}.) \quad \ldots$ & $93 \cdot 8$ & $94 \cdot 3$ \\
\hline $\mathrm{Fe}(00315 \mathrm{~cm}.) \quad \ldots$ & $69 \cdot 1$ & $69 \cdot 1$ \\
\hline $\mathrm{Cu}(.00298 \mathrm{~cm}.) \quad \ldots$ & 1010 & $102 \cdot 5$ \\
\hline $\mathrm{Zn}(00132 \mathrm{~cm})$. & $119 \cdot 2$ & $120 \cdot 0$ \\
\hline
\end{tabular}

It will thus be seen that within the limits of experimental errors the penetrating power of the tertiary beam is identical with that of a similar secondary beam from the same substance.

\section{The Homogeneity of the characteristic Tertiary Radiation.}

The tertiary beam from iron excited by the secondary homogeneous beam from copper was now cut down by thin aluminium sheets to test its homogeneity.

It was to be expected, even were the beam perfectly homogeneous, that after cutting down by a few plates the beam would appear slightly more peneirating, for the more oblique rays would suffer extinction to a greater extent than those passing through the absorber in a perpendicular direction.

It was not found possible to test for homogeneity to an exhaustive limit owing to the smallness of the readings in the later stages, but the results obtained show that for all practical purposes the beam may be regarded as homogeneous.

Plil. Mag. S. 6. Vol. 18. No. 103. July 1909. 
The results are tabulated below:-

TABLE II.

Iron as Tertiary Radiator ; Copper as Secondary Radiator.

\begin{tabular}{|c|c|}
\hline $\begin{array}{l}\text { Amount previously } \\
\text { absorbed by Aluminium. }\end{array}$ & $\begin{array}{c}\text { Subsequent absorption } \\
\text { by a sueet of Al (-vU297; } \\
\text { cun. thick. }\end{array}$ \\
\hline None. & 55.6 per cent. \\
\hline $55 \cdot 6$ per cent. & $55 \cdot 7 \quad "$ \\
\hline $80 \cdot 3 \quad$ & $555 \quad$ \\
\hline $94 \cdot 0$ & $550 \quad$, \\
\hline
\end{tabular}

Previous experiments have shown that associated with the homogeneous secondary radiation from a metal of the group $\mathrm{Cr}-\AA \mathrm{Ag}$ is a small proportion of scattered radiation, the relative ionizations produced by the homogeneous and scattered portions being about $150: 1$.

If the secondary beam from iron be absorbed by say - $0104 \mathrm{~cm}$. aluminium, then while the homogeneous portion will be absorbed to the extent of about 90 per cent. the scattered portion will only be absorbed by about 30 per cent., giving an absorption of the whole beam of 89.6 per cent. (the absorption being measured by the relative diminution in ionization); so that the relative ionizations produced by the residual homogeneous and scattered portions respectively will now be as $21 \cdot 4: 1$, and a sheet of 01.04 aluminium would now only absorb about $87 \cdot 4$ per cent. of the whole beam, and this increase in penetrating power would become more and more pronounced as further absorptions took place.

In a corresponding case of the tertiary beam from iron excited by copper radiation, the amount of scattered copper radiation in the beam if present at all will not be present to so great an extent since the copper radiation will not penetrate to anything like the same depth in the iron as an ordinary primary radiation, though on the other hand the ionization produced by beams of scattered primary radiation and of scattered copper radiation conveying equal amounts of energy per second through unit volume of air, will not be equal; the scattered copper radiation being more easily absorbed will produce the greater ionization.

No direct evidence has yet been obtained that when the normal tertiary radiation from iron is excited by homogeneous radiation from copper, any of the copper radiation itself is 
seattered by the iron; its presence in the beam wonld be difficult to detect for a small percentage of copper radiation in the beam would produce a very minute change in its absorption coefficients. The figures given in Table II. therefore do not preclude the possibility of a small percentage of the ionization being due to scattered copper radiation.

\section{Independence of the Pentrating Power of the Exciting Radiation.}

Experiments were made to test whether the penetrating power of the tertiary radiation emitted by a substance depended in any way upon the penetrating power of the exciting secondary beams. In the first test, iron was chosen as the tertiary radiator, copper and arsenic as the secondary radiators. The radiation from arsenic being about twice as penetrating as that from copper.

In the second test chromium was taken as the tertiary radiator, and iron, copper, and arsenic as secondary radiators; the radiations from each of these substances being more penetrating than that from chromium, the radiation from arsenic being about four times as penetrating as that from iron.

The results are tabulated below :-

TABLE III.

Iron as Tertiary Radiator.

\begin{tabular}{|c|c|c|}
\hline $\begin{array}{l}\text { Secondary } \\
\text { Radiator. }\end{array}$ & $\begin{array}{l}\text { Absorption coefficient } \\
\text { of the Secondary Radia- } \\
\text { tion by Aluminium. }\end{array}$ & $\begin{array}{l}\text { Percentage Absorption } \\
\text { of the 'Tertiary Radia- } \\
\text { tion by ( } 00297 \mathrm{~cm} \text {.) Al. }\end{array}$ \\
\hline Copper .... & $128 \cdot 9$ & $55 \cdot 6$ \\
\hline Arsenic ....... & 60.7 & $55 \cdot 4$ \\
\hline
\end{tabular}

TABLE IV.

Chromium as Tertiary Radiator.

\begin{tabular}{|c|c|c|}
\hline $\begin{array}{l}\text { Secondary } \\
\text { Radiator. }\end{array}$ & $\begin{array}{l}\text { Absorption coeffieient } \\
\text { of the Secondary Radia- } \\
\text { tion by Alumiuium. }\end{array}$ & $\begin{array}{l}\text { Percentage absorption } \\
\text { of the 'Tertiary Radia- } \\
\text { tion by }(\cdot 00297 \mathrm{~cm} .) \text { Al. }\end{array}$ \\
\hline Iron....$\ldots \ldots \ldots \ldots \ldots$ & 239 & $75 \cdot 1$ \\
\hline Copper ......... & $128 \cdot 9$ & $75 \cdot 3$ \\
\hline Arsenic ......... & $60 \cdot 7$ & $75 \cdot 1$ \\
\hline
\end{tabular}


From these results it will be seen that the penetrating power of the tertiary radiations is uninfluenced, so far as can be measured, by variations in the penetrating power of the exciting secondary beams; they further show that if any secondary radiation is scattered by the tertiary radiator, the ionization it produces is small compared with that produced by the tertiary radiation.

This result is analogous with that obtained with secondary beams*.

It has thus been shown that the characteristic tertiary radiation from iron is identical with the characteristic secondary radiation from iron in its penetrating power, its homogeneity, and in its independence of variations in the penetrating power of the exciting radiation.

Similar results were obtained with copper as a tertiary radiator.

\section{Connexion between the Secondary and Tertiary Radiators.}

A series of experiments was now undertaken in which the several members of the group of metals $\mathrm{Cr}-\mathrm{Ag}$ were used as secondary radiators, the tertiary radiators being also chosen from among the earlier members of the same group.

By referring to column 1 , Table $V$. it will be seen that the absorption coefficients by aluminium of the radiations from the metals of this group indicate a wide range of penetrating powers, so that it was reasonable to expect that for each tertiary radiator there would be at least some secondary radiations sufficiently penetrating to cause it to emit its characteristic, radiation.

The method of experimenting was as follows:-The secondary radiators successively placed in the position $\mathbf{R}_{\mathbf{I}}$ (see fig. 1) were subjected to the primary rays proceeding from the anticathode $A, R_{2}$ being temporarily removed. The ratio of the deflexions of the gold-leaves in the electroscopes $\mathrm{E}_{2}$ and $\mathrm{E}_{1}$ obtained from the microscope readings was determined in the case of each radiator; let $r_{1}$ be the value of this ratio and $r_{1}^{\prime}$ be the value of the ratio with no metallic radiator in the position $R_{1}$, the air in its neighbourhood acting as a source of secondary radiation.

Next, the particular tertiary radiator under. examination was placed in the position $R_{2}$ (as previously defined), and the secondary radiators were again in tarn subjected to the primary rays. Ionization was now produced in the chamber I and deflexions of the gold-leaf in electroscope $\mathbf{E}_{3}$

* Barkla \& Sadler, Phil. Mag. Oct. 1908, pp. 550-584. 
were obtained. Let the value of the ratio of the deflexions of the gold-leaves in $\mathrm{E}_{3}$ and $\mathrm{E}_{1}$ be $r_{2}$, and when the tertiary radiator was removed and the air alone in its neighbourhood acted as a source of tertiary rays, let the corresponding value of the ratio be $r_{2}^{\prime}$.

The tertiary radiator $R_{2}$ was then replaced and the ratio $r_{2}$ again found, and then finally removing $R_{2}$ the readings for the ratio $r_{1}$ were repeated.

Working with an X-ray bulb, having an auxiliary sparkgap, it was found that in the steady state the two sets of values for $r_{1}$ and likewise those for $r_{2}$ showed agreement to within 2 per cent.

In no case was the air-effect $r_{1}^{\prime}$ more than 1 per cent. of the value of $r_{1}$, in most cases less than $\frac{1}{4}$ of 1 per cent.; and in no case was the air-effect $r_{2}{ }^{\prime}$ more than 2 per cent. of the value of $r_{2}$ when the characteristic homogeneous radiation was excited.

In those cases where the penetrating power of the secondary beam did not exceed that of the characteristic radiation from the tertiary radiator employed, the air-effect $r_{2}{ }^{\prime}$ became of considerable importance, being as high as $\frac{1}{4}$ of $r_{2}$ in some cases. The author hopes to obtain more reliable data in these particular cases in the course of further experiments.

It will be seen later, however, that an accurate knowledge of these particular data is not essential in the present investigation.

It was estimated that if in all other cases $\frac{1}{2}$ of the aireffect was taken in addition to the normal leakage, and this subtracted in each case from the direct effect when the metallic radiator was in position, the resulting ratios finally obtained would be accurate to at least 2 per cent. If $a$ denote the ratio of the normal leakage in any given time in the electroscope $\mathrm{E}_{2}$ to the deflexion in $\mathrm{E}_{1}$ in the same time, with a primary beam as during the actual experiment, then since the normal leakage is compensated for in $\mathrm{E}_{3}$, the ratio of the ionizations in the electroscopes $\mathrm{E}_{3}$ and $\mathrm{E}_{2}$ due to the homogeneous radiations

$$
=\frac{r_{2}-\frac{1}{2} r_{2}^{\prime}}{r_{1}-\left[\frac{1}{2} r_{1}^{\prime}+a\right]}=\mathrm{R} \text { (say). }
$$

If the absorption coefficient of the homogeneous radiation from a given tertiary radiator by $\mathrm{Al}$ be denoted by $\lambda_{2}$, and that of the exciting secondary radiation by $\lambda_{1}$, then as long as $\lambda_{1}=$ or is $>\lambda_{2}$ the value of $R$ is quite small and approximately constant. As $\lambda_{1}$ decreases through the value $\lambda_{2}$ we get a rapid increase in the value of $R$, and for a comparatively 
small subsequent increase in penetrating power of the secondary beam, values of $\mathrm{R} 30$ to 40 times as big as the previous stearly values are obtained; this increase corresponding to the excitation of the characteristic tertiary radiation.

Let us consider the tertiary radiation emitted normally from a given radiator of area $S$ upon which a uniform parallel beam of secondary rays is incident normally.

Let us define a quantity $k$, such that the fraction of the energy of the secondary beam passing normally through a thin layer $\delta x$ of the tertiary radiator which is transformed into tertiary radiation is $k \delta x$. Thus, if $I$ be a measure of the energy passing normally per second through unit area of the tertiary radiator at a depth $x$ below the surface, the energy transformed per second in a layer $\delta x=\mathrm{I} k \delta x$.

Now Barkla * has shown that when this homogeneous type of radiation is excited, it is practically evenly distributed in all directions : consequently, the energy passing per second as tertiary radiation from the layer $\delta x$ through the tissue-paper-covered window of an electroscope of the Wilson type (I being constant over the whole area of the radiator)

$$
=\frac{\omega}{4 \pi} \mathrm{SI} k \delta \delta e^{-\lambda_{2} x}, \ldots \cdot \cdot \cdot \cdot
$$

where $\lambda_{2}$ is the absorption coefficient of the tertiary radiation by the material of which the tertiary radiator is composed, and $\omega$ is the mean solid angle subtended by the aperture of the electroscope at ali parts of the radiating area.

But if $I_{0}$ is a measure of the energy incident normally per second on unit area of the tertiary radiator at the surface,

$$
\mathrm{I}=\mathrm{I}_{0} e^{-\lambda_{1} x},
$$

where $\lambda_{1}$ is the absorption coefficient of the secondary beam by the material of which the tertiary radiator is composed, and the whole energy passing into the electroscope per second from the tertiary radiator

$$
\begin{aligned}
& =\frac{\omega}{4 \pi} \mathrm{SI}_{0} k \int_{0}^{\infty} e^{-\left(\lambda_{1}+\lambda_{2}\right) x} \cdot d x \quad . \quad . \quad . \\
& =\frac{\pi}{4 \pi} \mathrm{SI}_{0^{h}} \frac{1}{\lambda_{1}+\lambda_{2}} \cdot \cdot \cdot \cdot \cdot \cdot \cdot \cdot \cdot
\end{aligned}
$$

If now we remove the tertiary radiator, and place the electroscope previously used in the path of the secondary beam, with the centre of its tissue-paper-covered window occupying the position previously occupied by the centre of

* Barkla, Phil. Mag. Feb. 1908, pp. 288-296. 
the radiator, and with its plane perpendicular to the axis of the secondary beam, the energy passing per second through the window, if its area is $A$, is $I_{0} \mathrm{~A}$.

Therefore the ratio of the energy in the tertiary beam passing per second into the electroscope in the first position to the energy of the secondary beam passing per second into the electroscope in its second position

$$
=\frac{\omega \mathrm{S}}{4 \pi} \mathrm{A} \cdot \frac{k}{\lambda_{1}+\lambda_{2}} . \quad \text {. . . . . }
$$

There is considerable evidence that the ionization produced in a given volume of air by a beam of Röntgen radiation is approximately proportional to the absorption of that radiation by the air. It has been found * also that the ratio of the absorption coefficients of homogeneous beams of different penetrating powers by any two substances, $e \cdot g$. carbon and aluminium, in which no radiation of the homogeneous type is excited by the beam under consideration, is a constant. Also it has been found that the absorption of a beam of Röntgen rays by any substance depends only upon the quantity of matter present and not upon its state of aggregation.

It is assumed on the basis of these results, that the ionizations produced in a given volume of air by homogeneous beams of different penetrating powers are proportional to the absorption coefficients of these beams by carbon or aluminium.

Making this assumption, we have the ratio of the ionizaltions produced in the electroscope by the tertiary and secondary beams

$$
=\frac{\omega}{4 \pi} \frac{S}{A} \cdot \frac{k}{\lambda_{1}+\lambda_{2}} \cdot \frac{\beta}{\alpha} \cdot=\frac{\vartheta_{2}}{\vartheta_{1}} \text { (say). . . }
$$

where $\alpha$ and $\beta$ are the absorption coefficients by aluminium of the secondary and tertiary beams respectively. From (5) we find that $k$

$$
=\frac{\vartheta_{2}}{\vartheta_{1}} \cdot \frac{\alpha}{\beta} \cdot \frac{A}{S} \cdot \frac{4 \pi}{\omega} \cdot\left(\lambda_{1}+\lambda_{2}\right) .
$$

In the above calculations we have considered the special case of normal incidence and emergence, but, since we are dealing with radiators sufficiently thick to ahsorb the whole of the incident radiation, it is easy to show that the results $(4) ;(5),(6)$ are quite general for oblique incidence and emergence, where the incident and emergent beams make equal angles with the normal to the radiating surface.

$$
\text { * Barkla \& Sadler, Phil. Mag. May } 1909 .
$$


In order to deduce values of $k$ from the experimental data, it is necessary to know the values of $\alpha, \beta, \lambda$, and $\lambda_{2}$ for each of the tertiary radiators employed. $\alpha$ and $\beta$ are readily obtained for the whole series and likewise $\lambda_{1}$ and $\lambda_{2}$ for $\mathrm{Zn}$, $\mathrm{Cu}, \mathrm{Ni}$, and $\mathrm{Fe}$. In the case of $\mathrm{Cr}$ and $\mathrm{Co}$, being unable to obtain thin plates of these substances, the values for $\lambda_{1}$ and $\lambda_{2}$ could not be obtained directly but were deduced by the following method.

If the values of $\frac{\lambda_{2}}{\rho}$ (where $\lambda_{2}$ is the absorption coefficient by a substance of its own characteristic radiation and $\rho$ its density) for the substances $\mathrm{Fe}, \mathrm{Ni}, \mathrm{Cu}$, and $\mathrm{Zn}$ are plotted

Fig. 2.

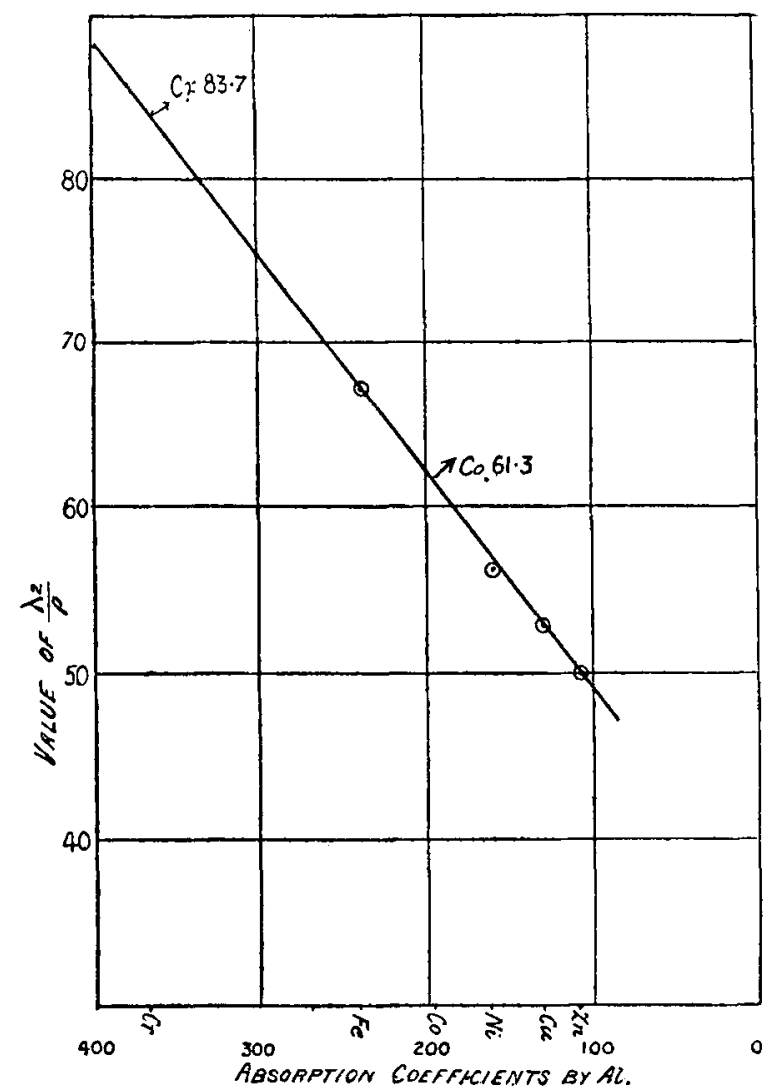

as ordinates, against the absorption coefficients for the radiations from these substances by $\mathrm{Al}$ as abscissæ, it is found that the points obtained lie on a straight line, as shown in fig. 2. 
The values of $\frac{\lambda_{2}}{\rho}$ for Co and Cr deduced from this graph are Co $(61 \cdot 3)$, Cr $(83 \cdot 7)$.

Moreover, a regular relationship is found to exist between the ratios of $\lambda_{1}$ for the radiations from consecutive inembers of the group $\mathrm{Cr}-\mathrm{Se}$ for each of the absorbers $\mathrm{Zn}, \mathrm{Cu}, \mathrm{Ni}$, and $\mathrm{Fe}$. Taking the values of the absorption coefficients for any three of these absorbers for the radiations from the group Cr-Se, values for the coefficients for the fourth absorber could be deduced, starting with a value of $\lambda_{2}$ as a basis and using these observed relationships. In no case was the discrepancy between the experimental and deduced values greater than 2 per cent.

In a similar manner the remaining values of the absorption coefficients for Co and $\mathrm{Cr}$ were deduced, taking the values of $\lambda_{2}$ obtained above as a basis for calculation in each case.

\section{TABLE $V$.}

\begin{tabular}{|c|c|c|c|c|c|c|c|c|c|c|c|c|c|}
\hline \multirow[b]{3}{*}{ RADIATORS. } & \multicolumn{7}{|c|}{ Values of $\underline{\lambda}$ used in calculation of $k$. } & \multicolumn{6}{|c|}{$\begin{array}{c}\text { Values of } \frac{\lambda^{\mathrm{J}}}{\text { used in calculation }} \\
\text { of the ratio } \frac{k}{\lambda^{\prime}}\end{array}$} \\
\hline & \multicolumn{13}{|c|}{ A BSORBERS. } \\
\hline & Al. & Cr. & $\mathrm{Fe}$. & Co. & $\mathrm{Ni}$. & $\mathrm{Cu}$. & $\mathrm{Zn}$. & Cr. & Fe. & Co. & $\mathrm{Ni}$. & Cu. & $\mathrm{Zn}$. \\
\hline Chromium.. & 367 & 544 & & & & & & & & & & & \\
\hline Iron $\ldots .$. & 239 & 2500 & 514 & & & & & 2150 & & & & & \\
\hline Cobalt ...... & 1932 & 2076 & 521 & 545 & & & & 1785 & 102 & & & & \\
\hline Nickel......... & $159 \cdot 5$ & 1730 & 2440 & 584 & 482 & & & 1490 & 2090 & 134.0 & & & \\
\hline Copper ...... & 128.9 & 1478 & 2080 & 2560 & 537 & 474 & & 1279 & 1798 & 2194 & 150 & & \\
\hline Zinc .......... & $106 \cdot 3$ & 227 & 1715 & 2172 & 2275 & 497 & 361 & 1072 & 1485 & 1875 & 1936 & $120 \cdot 1$ & \\
\hline Arsenic ...... & $60: 7$ & 755 & 1040 & 1333 & 1422 & 1575 & 1464 & 666 & 915 & 1161 & 1232 & 1356 & 1260 \\
\hline Selenium ... & $51 \cdot 0$ & 652 & 903 & 1159 & 1211 & 1340 & 1258 & 577 & 800 & 1014 & 1055 & 1157 & 1080 \\
\hline Silver ......... & 6.75 & & & & & 214 & $195 \cdot 1$ & & & & & $189 \cdot 2$ & $170 \cdot 0$ \\
\hline
\end{tabular}

It will be seen later that it is desirable to know what fraction of the absorption of the exiting radiation by the material of the radiator is directly concerned in the transformations of energy which are taking place during the 
passage of the secondary beam through the substance of the tertiary radiator.

It has been found ${ }^{*}$ that if the values of $\lambda_{1}$ for the radiations from the group $\mathrm{Cr}$ to $\mathrm{Ag}$ for any absorber, such as silver, ir. which no homogeneous rudiation is excited by the radiations from any member of the group, be plotted as ordinates against the corresponding values of $\lambda_{1}$ for aluminium, in which also no homogeneous radiation is excited, as abscissæ ; the points so obtained lie on straight lines, and these straight lines pass through a common point.

Similarly, if we plot as ordinates the values of $\lambda_{1}$ for any of the early members of the group $\mathrm{Cr}-\mathrm{Ag}$ as absorber, in which the homogeneous type of radiation is excited by the radiation from those members of the group of higher atomic weight; it has been found, that up to the point corresponding to the atomic weight of the absorber, the relation is also linear, and if the straight line be produced, it passes through the common point previously mentioned. The values of $\lambda_{1}$ for the radiation from the radiators of higher atomic weight are abnormally increased, the increase being attendant upon the excitation of tertiary radiation.

This increase is discussed in the paper on "The Absorption of X Rays" previously referred to.

In the actual experiments to determine the values of $R$ with the various combinations of secondary and tertiary radiators, it was found necessary to alter the position of the quadrants of the tertiary electroscope from time to time, owing to a slight shift of zero, due to small progressive variations in the applied potentials. In this way small changes in the sensitiveness of the instrument were introduced. The sensitiveness conld, however, be maintained constant during a period of three or four hours during any given day.

In order to obtain true relative values for the ionizations, the secondary rudiation from arsenic was made to fall upon each of the tertiary radiators placed successively in the position $R_{2}$, the sensitiveness of the electroscope remaining constant during this series of observations. Values of $\mathrm{R}$ were obtained in this way for $\mathrm{Zn}, \mathrm{Cu}, \mathrm{Ni}$, and $\mathrm{Fe}$ as tertiary radiators, the surfaces in each case being brightly polished, of the same size, and thick enough to totally absorb the incident beam. These values of $R$ plotted as ordinates against the atomic weight of the radiators as auscissæe, were found to lie on a smooth curve (see fig. 3).

In the case of $\mathrm{Cr}$ and $\mathrm{Co}$, being unable to obtain them pure in the form of flat plates, radiators were made in the

* Barkla \& Sadler, Phil. Maug. Mry 1909. 
following manner. A flat plate of aluminium, of the same size as the required radiator, was covered with a thin layer of

Fig. 3.

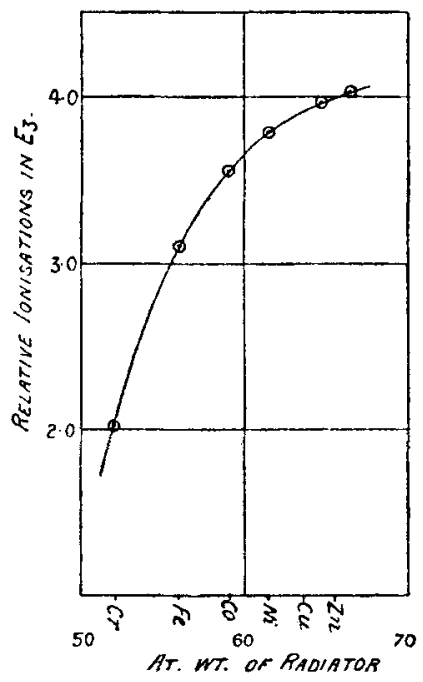

adhesive (previously tested and found to emit no detectable radiation of the homogeneous type), and then the metals, finely powdered, were pressed into this layer, the surface being covered with powdered metal. A sample radiator prepared with pure iron filings in this way emitted a tertiary radiation indistinguishable (by absorption tests) from that produced from a plate of the metal. This, however, is quite to be expected since practically the whole of the tertiary radiation from iron is obtained from a layer $\cdot 003 \mathrm{~cm}$. thick.

But the value of $R$ for a prepared plate of iron filings is a little less than that for a flat polished plate of iron of equal size placed in an identical position, owing to the irregularities of the surface reducing the effective area. Three equal prepared plates of Co, $\mathrm{Fe}$, and $\mathrm{Cr}$ and a polished plate of iron were therefore used, the powders being as nearly as possible equally fine, and the relative values of $R$ obtained. From a comparision of the two values of $R$ for iron, values of $R$ for polished plates of Co and $\mathrm{Cr}$ could be deduced, and these were found when plotted to lie almost exactly upon the curve in fig. 3.

From the set of values thus obtained the true relative values of $\mathbf{R}$ for the complete series of experiments previously described were deduced and are given below in Table VI. 
TABle VI.

\begin{tabular}{|c|c|c|c|c|c|c|c|c|c|c|c|c|}
\hline \multirow[b]{3}{*}{$\begin{array}{l}\text { SECONDAEY } \\
\text { RADIATORS. }\end{array}$} & \multicolumn{6}{|c|}{$\begin{array}{l}\text { Values of . R. calculated from } \\
\text { the total Ionization in the } \\
\text { lonization-chamber } I \text {. }\end{array}$} & \multicolumn{6}{|c|}{$\begin{array}{l}\text { Values of . } \mathbf{R}^{\prime} \text {. calculated } \\
\text { from the normal tertiary } \\
\text { Ionjzation alone in the } \\
\text { lonization-chamber I. }\end{array}$} \\
\hline & \multicolumn{12}{|c|}{ Tertari Radiators. } \\
\hline & Or. & Fe. & Co. & $\mathrm{Ni}$. & Cu. & $\mathrm{Zn}$. & Cr. & Fe. & Co. & Ni. & $\mathrm{Cu}$. & Zn. \\
\hline & $\cdot 076$ & $\cdot 107$ & $\cdot 109$ & $\cdot 143$ & -1 & -1 & - & - & - & - & - & - \\
\hline Fe .......... & $1 \cdot 76$ & .076 & .091 & $\cdot 118$ & $\cdot 126$ & $\cdot 124$ & 168 & 一 & - & - & - & - \\
\hline Co …....... & 181 & $\cdot 42$ & $\cdot 097$ & $\cdot 118$ & $\cdot 100$ & $\cdot 106$ & 1.73 & 327 & - & - & - & - \\
\hline ........... & 1.95 & 264 & $\cdot 466$ & $\cdot 101$ & .084 & $\cdot 087$ & 1.87 & $2 \cdot 45$ & .366 & -1 & - & - \\
\hline $\mathrm{Cu} \quad \ldots . . . . .$. & 1.92 & $2 \cdot 64$ & 3.00 & .582 & .093 & $\cdot 110$ & 1.84 & 255 & $2 \cdot 90$ & $\cdot 472$ & - & - \\
\hline $\mathrm{Zn} \ldots \ldots \ldots$ & $2 \cdot 02$ & $2 \cdot 88$ & $3 \cdot 37$ & 353 & .528 & $\cdot 115$ & 1.94 & $2 \cdot 79$ & $3 \cdot 27$ & $3 \cdot 42$ & $\cdot 488$ & - \\
\hline Ga ?.......... & $\cdots$ & $\cdots$ & $\cdots$ & $\cdots$ & $\cdots$ & $\cdots$ & $\cdots$ & $\cdots$ & $\cdots$ & $\cdots$ & $\cdots$ & $\cdots$ \\
\hline As $\quad \ldots . . . . . .$. & 2002 & $3 \% 10$ & $3 \cdot 57$ & $3 \ddot{79}$ & $3 \dddot{97}$ & 403 & 1.94 & 301 & $3 \ddot{47}$ & $3 \because 68$ & $3 \ddot{8} 6$ & 3.92 \\
\hline Se $\quad \ldots . . . . . .$. & 1.86 & $2 \cdot 87$ & $3 \cdot 11$ & $3 \cdot 47$ & 361 & $3 \cdot 86$ & $1 \cdot 78$ & $2 \cdot 78$ & $3 \cdot 01$ & $3 \cdot 36$ & 3.50 & 375 \\
\hline$\cdots$ & $\cdots$ & $\ldots$ & $\cdots$ & $\cdots$ & $\cdots$ & $\ldots$ & $\ldots$ & $\cdots$ & $\cdots$ & $\cdots$ & $\cdots$ & $\ldots$ \\
\hline$\cdots$ & $\cdots$ & $\cdots$ & $\cdots$ & $\cdots$ & $\cdots$ & $\cdots$ & $\cdots$ & $\cdots$ & $\cdots$ & $\cdots$ & $\cdots$ & $\cdots$ \\
\hline$\cdots$ & $\cdots$ & $\cdots$ & $\cdots$ & $\cdots$ & $\cdots$ & $\cdots$ & $\cdots$ & $\cdots$ & $\cdots$ & $\cdots$ & $\cdots$ & .. \\
\hline$\cdots$ & ... & $\ldots$ & ... & $\cdots$ & $\cdots$ & $\ldots$ & $\cdots$ & $\cdots$ & $\cdots$ & $\cdots$ & $\cdots$ & $\cdots$ \\
\hline$\cdots$ & $\cdots$ & $\cdots$ & $\cdots$ & $\cdots$ & $\cdots$ & $\cdots$ & $\cdots$ & $\cdots$ & $\cdots$ & $\cdots$ & $\cdots$ & $\cdots$ \\
\hline$\dddot{A g} \quad \ldots . . . . .$. & $\cdots$ & $\dddot{\cdots}$ & $\ddot{-}$ & $\ddot{-}$ & $1 \cdot 35$ & $1 \cdot 40$ & $\ddot{-}$ & $\cdots$ & $\cdots$ & $\cdots$ & $1 \ddot{24}$ & $1 \ddot{29}$ \\
\hline
\end{tabular}

However, it is found that when zinc is used as a tertiary radiator and the secondary beams from iron to zine fall upon it successively, a small value $R$ is obtained, even though none of the characteristic homogeneous radiation is excited by these secondary beams. The ionization in the chamber $I$ in these cases is due, partly to the scattering of the secondary radiation, partly to the production of tertiary radiation by the small percentage of scattered primary radiation in the secondary beam employed, and possibly in part to the production of a feeble type of very easily absorbed radiation much softer than the normal homogeneous radiation from zinc.

All evidence obtained up to the present points to the persistence of these residual effects even when the exciting secondary beam is sufficiently penetrating to produce the characteristic zinc radiation, and since in the calculation of $k$ we only require a measure of the homogeneous tertiary radiation excited by the homogeneous secondary beam, these residual effects have been estimated and subtracted in each case.

The values of $R$ finally obtained, which we may denote by $R^{\prime}$, are given in Table VI. 
The next step was to calculate in some one particular case an actual value of $k$ from the data obtained by using a suitable pair of secondary and tertiary radiators. A that polished plate of pure copper $(3.04 \mathrm{~cm} . \times 3.03 \mathrm{~cm}$. $)$ was mounted on a fine aluminium stem and placed in the position $R_{2}$. The ionization-chamber connected to the tertiary electroscope $\mathrm{E}_{3}$ was removed and replaced by the electroscope $\mathrm{E}_{2}$. The distance from the centre of the radiator to the centre of the tissue-paper-covered window of $\mathrm{E}_{2}$ was $4.7 \mathrm{~cm}$., the area of the window being the same as in previous experiments. 'The plane of the radiator being vertical with the normal to its surface bisecting the angle between the axis of the secondary beam and the normal to the aperture at its centre, of the electroscope $\mathrm{E}_{2}$.

From the relative positions of the tertiary radiator and the window of $\mathrm{E}_{2}$ (carefully determined) a value of $\omega$ was calculated and found to be approximately $\cdot 222$.

The ratio of the ionizations in the electroscopes $\mathrm{E}_{2}$ and $\mathrm{E}_{1}$ was then determined, allowance being made for the air-effect in the manner previously explained, and the mean of several readings, none of which differed by more than 2 per cent. from the mean, was found to be $\cdot 115$.

The tertiary radiator was then removed and the electroscope $\mathrm{E}_{2}$ was placed with its window perpendicular to the axis of the secondary beam, the centre of the window being in the position previously occupied by the centre of the tertiary radiator. Since the area of the window of $\mathrm{E}_{2}$ was almost exactly equal in shape and size to the area of the tertiary radiator projected in a plane perpendicular to the axis of the secondary beam, the ionization will correspond to the mean intensity over the area of the tertiary radiator in the previous part of the experiment. The mean value of the ratio of the deflexions in $\mathrm{E}_{2}$ and $\mathrm{E}_{1}$ was now equal to $11 \cdot 48$.

Substituting the values of $\alpha, \beta, \tilde{\lambda}_{1}$ and $\lambda_{2}$ from Table V., we find

$$
k=\frac{\cdot 115}{11 \cdot 48} \times \frac{60 \cdot 7}{128 \cdot 9} \times \frac{6 \cdot 0}{9 \cdot 2} \times \frac{4 \pi}{222} \times(1575+488)=361 .
$$

The value of $\lambda_{2}$ was increased by 3 per cent. to allow for the obliquity ; the value of $k$ was, however, affected by less than 1 per cent.

In the series of experiments previously mentioned, in the course of which a copper radiator was subjected to secondary beams from the group of metals $\mathrm{Cr}-\mathrm{Ag}$, we obtained values of $\mathbf{R}^{\prime}$ with arsenic as radiator, and in these cases

$$
k=\frac{\mathrm{R}^{\prime}}{\mu} \cdot \frac{\alpha}{\beta} \cdot \frac{\mathrm{A}}{\mathrm{S}^{\prime}} \cdot \frac{4 \pi}{\omega^{\prime}}\left(\lambda_{1}+\lambda_{2}\right),
$$


where $\mu$ is the ratio of the sensibility of the electroscope $E_{3}$ to that of $\mathrm{E}_{2} ; \mathrm{S}^{\prime}$ is the area of the tertiary radiator and $\omega^{\prime}$ the mean solid angle subtended by the radiator $R_{2}$ at the window of the ionization-chamber $I$; and $\alpha, \beta, \lambda_{1}$, and $\lambda_{2}$ as defined above and corrected for the obliquity of the rays. This correction was determined experimentally.

Equating these values of $k$, we find

$$
\frac{4 \pi \mathrm{A}}{\mu \omega^{\prime} \mathrm{S}^{\prime}}=\cdot 093 \text {, }
$$

and we may therefore write

$$
k=\cdot 093 \times \mathrm{R}^{\prime} \times \frac{\alpha}{\beta} \times\left(\lambda_{1}+\lambda_{2}\right) .
$$

The value of $k$ calculated from the data given in Tables V. and VI. are given below.

\begin{tabular}{|c|c|c|c|c|c|c|c|c|c|c|c|c|}
\hline \multirow[b]{3}{*}{$\begin{array}{l}\text { SECONDARY } \\
\text { RADIATORB. }\end{array}$} & \multicolumn{6}{|c|}{ Values of $k$. } & \multicolumn{6}{|c|}{ Values of $\frac{k}{\lambda^{\prime \prime}}$} \\
\hline & \multicolumn{12}{|c|}{ ThRTIARY RADIATORS. } \\
\hline & $\mathrm{Cr}$. & Fe. & Co. & $\mathrm{Ni}$. & Cit. & $\mathrm{Zn}$. & Cr. & Fe. & Co. & Ni. & Cu. & $\mathrm{Zn}$. \\
\hline Iron ...... & 378 & & & & & & $\cdot 176$ & & & & & \\
\hline Cobalt ...... & 275 & $31 \cdot 5$ & & & & & $\cdot 154$ & 309 & & & & \\
\hline Nickel ....... & 216 & 526 & $38 \cdot 4$ & & & & $\cdot 145$ & $\cdot 252$ & $\cdot 287$ & & & \\
\hline Copper. & 162 & 403 & 670 & $43 \cdot 2$ & & & $\cdot 127$ & 225 & $\cdot 305$ & $\cdot 288$ & & \\
\hline Zinc $\ldots . . . . .$. & 1175 & 307 & 528 & 657 & $43 \cdot 0$ & & $\cdot 109$ & 207 & .282 & $\cdot 340$ & $\cdot 358$ & \\
\hline Arsenic ....... & $50 \cdot 5$ & 137 & 227 & 288 & 390 & 412 & $\cdot 0757$ & $\cdot 150$ & $\cdot 195$ & $\cdot 233$ & $\cdot 288$ & 327 \\
\hline Selenium ... & $36 \cdot 0$ & $96 \cdot 0$ & $151 \cdot 0$ & 197 & $26 \%$ & 300 & $\cdot 0624$ & 120 & $\cdot 149$ & $\cdot 187$ & .231 & $\cdot 278$ \\
\hline Silver ....... & & & & & $5 \cdot 35$ & $5 \cdot 30$ & & & & & $\cdot 0282$ & .0313 \\
\hline
\end{tabular}

TABLE VII.

NoTk. - In the case of each tertiary radiator, when the secondary beam is only just more penerrating than the radiation characteristic of the tertiary radiator, the value of $k$ is small and cannot be determined nearly as accurately as the later values; nor can the value of $\lambda^{\prime}$ corresponding to the initial small value of $k$ be determined with accuracy. Consequently the initial values of $\frac{k}{\lambda^{\prime}}$ are somewhat uncertain, and it is impossible to determine from them whether $\frac{k}{\lambda^{\prime}}$ for any given tertiary radiator rises to a maximum, and then decreases in value, or whether it continuously decreases from the initial value. 
If the values of $k$ for each tertiary radiator are plotted as ordinates against the absorption coefficients by aluminium of the exciting secondary beams as abscissæ, we obtain the graphs shown in tig. 4.

Fig. 4.

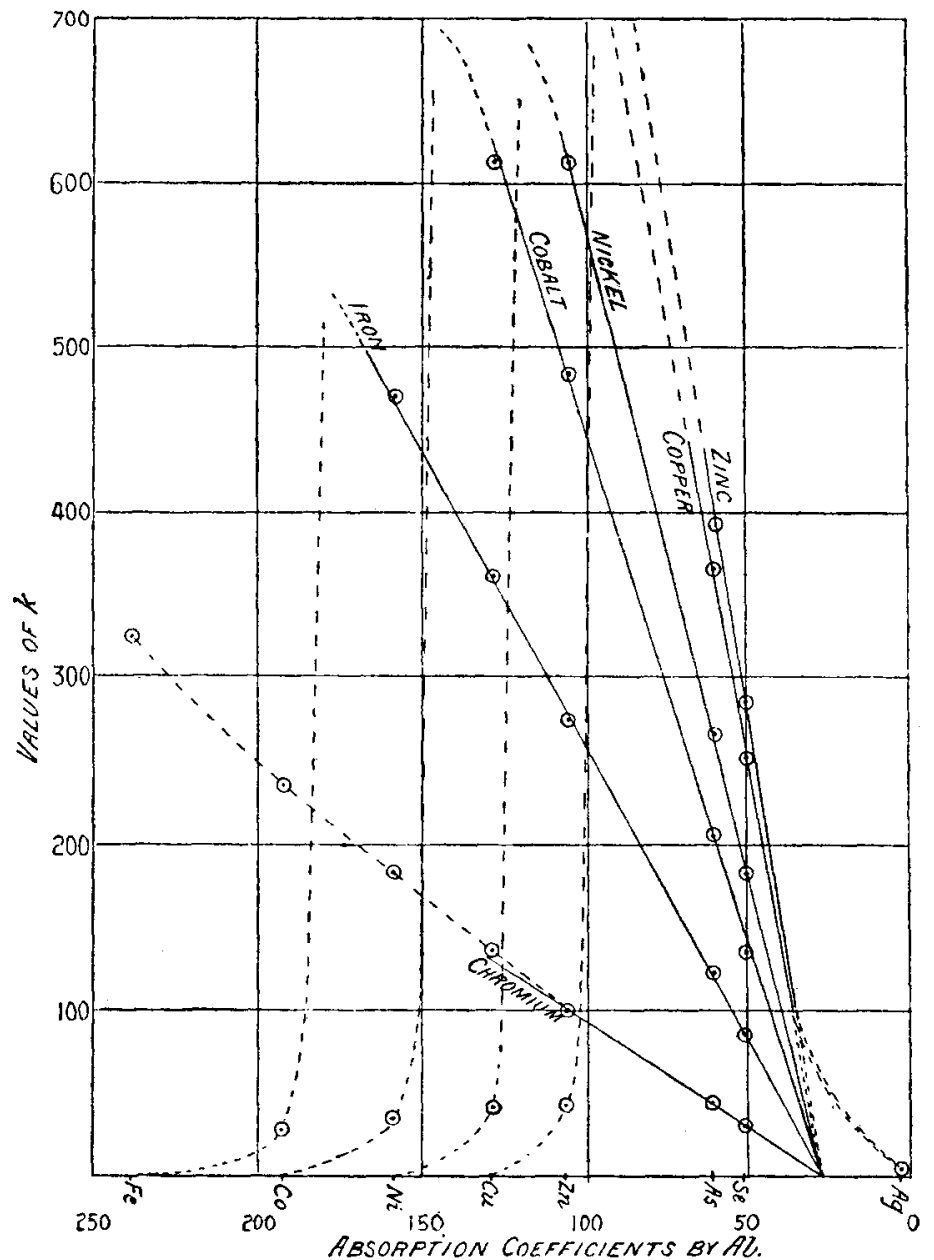

If $\lambda_{2}$ be the value of the absorption coefficient by $\mathrm{Al}$ of the characteristic homogeneous radiation from any substance $A$ and $\lambda_{1}$ that of the exciting radiation (also homogeneous), 
an examination of the graphs in fig. 4 leads to the following conclusions:-

(1) If $\lambda_{1}$ is equal to or greater than $\lambda_{2}$, the intensity of the homogeneous radiation emitted by $A$ is inappreciable.

(2) If $\lambda_{1}$ is slightly less than $\lambda_{2}$ the intensity is measurable but still small.

(3) For a further slight decrease in $\lambda_{1}$ a very rapid increase in the intensity of the radiation from $A$ takes place, and for a value of $\lambda_{1}$ not greatly less than $\lambda_{2}$ the intensity reaches a maximum value.

(4) Beyond this point, over a considerable range, as $\lambda_{I}$ decreases the intensity decreases as a linear function of $\lambda_{1}$. For this range the relationship may be represented by $k=a\left(\lambda_{1}-b\right)$, where $a$ and $b$ are constants. For the group of tertiary radiators employed, $b$ has the same value for each member of the group, while $a$ increases with the increase of the atomic weight of the tertiary radiator.

But the absorption by $\mathrm{Al}$ of the radiation from the group of metals $\mathrm{Cr}-\mathrm{Ag}$ is proportional to the absorption by air of these radiations, as previously mentioned; and it has been shown that the intensity of the homogeneous radiation excited in a thin sheet of copper by a primary beam is proportional to the ionization produced in air by the same beam * : we may, therefore, over this range, write $k=a(c i-b)$, where $i$ is a measure of the ionization produced in 1 c. c. of air by the exciting beam, and $c$ the ratio of the absorption by 1 c.c. of air to the ionization produced in it in consequence of that absorption, $a$ and $b$ having the same values as before. (It will be seen from the $\mathrm{Zn}$ and $\mathrm{Cu}$ curves that there is a departure from this linear relationship for very penetrating beams.)

When a secondary homogeneous Röntgen beam falls normally upon a tertiary radiator, the amount of energy absorbed per sec. per unit area of its surface in a layer of thickness $\delta x$ at a distance $x$ below the surface is $I \lambda_{1} \delta x$, where $I$ is the energy crossing unit area of the surface per second at the depth $x$ below the surface and $\lambda_{1}$ is the absorption coefficient by the substance of the tertiary radiator of the secondary beam. If, however, we confine our attention to the absorption which is directly involved in the process of emission of tertiary rays, we must substitute $\lambda^{\prime}$ for $\lambda_{1}$, where $\lambda^{\prime}$ is the increase in the value of the absorption coefficient, and the amount of energy so absorbed per second in this layer is $\left[\lambda^{\prime} \delta x\right.$. [The values of $\lambda^{\prime}$ are given in Table V.]

But the amount of energy emitted as tertiary radiation

* Barkla \& Sadler, Phil. Mag. Oct. 1908, pp. 550-584. 
per second from this layer in consequence of such absorption is, as we have seen, $I k \delta x$.

Therefore $\frac{k}{\lambda^{\prime}}$ is a measure of that fraction of this special absorption of energy which is re-emitted as energy of tertiary radiation.

The values of $\frac{k}{\lambda^{\prime}}$ are given in Table VII., and the curves obtained by plotting these values as ordinates against the values of $\lambda_{1}$ by $A l$ of the exciting radiation as abscisse are shown in fig. 5 .

Fig. 5.

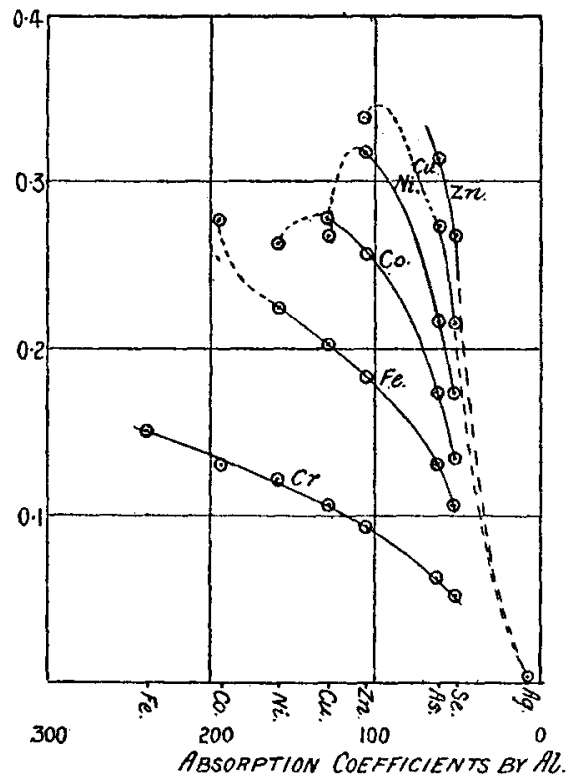

For any given tertiary radiator the value of $\frac{k}{\lambda^{\prime}}$ attains to a maximum for a value of $\lambda_{1}$ in the neighbourhood of that which gives a maximum value of $k$. As the exciting radiation becomes more penetrating this fraction diminishes slowly at first and then more rapidly.

Taking the case of copper as a tertiary radiator for example, the maximum value of the fraction which corresponds to a value of $\lambda_{1}$ about 89 is nearly $2 / 5$, when $\lambda_{1}$ decreases to 51 the fraction has fallen to about $1 / 4$, and for a value of $\lambda_{1}=6.96$ to about $1 / 40$.

At the present stage of the inquiry the cause of this rapid Plial. Mag. S. 6. Vol. 18. No. 103. Jully 1909. 
decrease in the value of $\frac{k}{\lambda}$, can merely be a matter for conjecture, but it is hoped that the data obtained in subsequent experiments will throw more light upon the phenomena*.

It will be observed that in determining these relationships the atomic weight of nickel is nowhere assumed, but the results obtained all point to the conclusion that the behaviour of nickel, whether as radiator or absorber of X-rays, is such that we should expect its atomic weight to lie between those of cobalt and copper.

The evidence for this, obtained during the course of these experiments, may be briefly summarized as follows :-

(a) The secondary homogeneous radiation from cobalt excites no homogeneous tertiary radiation in nickel.

(b) The secondary homogeneous radiation from nickel excites no homogeneous tertiary radiation in nickel.

(c) The secondary homogeneous radiation from nickel does excite homogeneous tertiary radiation in cobalt, and to an extent to be expected for the radiation from a substance of atomic weight about midway between those of cobalt and copper. that

But it has been shown for the group of metals $\mathrm{Cr}-\mathrm{Ag}$

(1) The penetrating power of the radiation characteristic of any member of the group increases with its atomic weight $\dagger$.

(2) The radiation characteristic of a substance is only excited by a more penetrating radiation $\ddagger$.

If the atomic weight of nickel were greater than that of cobalt, then by (1) we should expect to find its characteristic radiation to be more penetrating than that of cobalt, and consequently by (2) that the radiation from nickel should excite in cobalt its characteristic radiation, while the radiation from cobalt should not excite the radiation characteristic of nickel. If, on the other hand, the atomic weight of nickel were less than that of cobalt, then the results would be the reverse of the former.

It has been suggested that the anomalous behaviour of

* Note. Experiments now in progress indicate that when the exciting beam is more penetrating than the radiation characteristic of the tertiary radiator, part of the energy absorbed reappears as an easily absorbed corpuscular radiation, and this effect becomes more pronounced as the exciting beam becomes more penetrating.

† Barkla \& Sadler, Phil. Mag. Sept. 1907, pp. 812-828; also Phil. Mag. May 1909.

I Barkla \& Sadler, Phil. Mag. Oct. 1908 ; also present paper. 
nickel may be due to oxidation of the cobalt or the nickel. The author has found, however, that if iron be used as a tertiary radiator, and the secondary radiations from the group of metals $\mathrm{Cr}-\mathrm{Ag}$ successively fall upon the iron in the manner described earlier in the paper, the results obtained are exactly similar whether the radiator is coated with a layer of rust or brightly polished, the relative values of $k$ being the same in the two cases.

The result $(b)$ would not have been obtained if the nickel experimented with had contained an impurity which emitted a charucteristic type of radiation " harder" or "softer" than that characteristic of nickel. For the harder component of the secondary beam (whether due to the nickel or the impurity) would have excited the softer component radiation in the tertiary radiator, and this would have been detected if the impurity had been present to any appreciable extent.

\section{Summary of Results.}

(1) The characteristic Röntgen radiation from a substance is found to be identical in character whether it is emitted as a secondary or a tertiary radiation. In each case $(a)$ the radiation is homogeneous, $(b)$ the absorption coefficients of the radiation by other substances are the same, and independent of the penetrating power of the exciting radiation by which these homogeneous beams are produced.

(2) Using the homogeneous secondary beams emitted by the members of the group of metals $\mathrm{Cr}-\mathrm{Ag}$, excited by suitable primary beams, the emission of tertiary radiation by the earlier inembers of the group $\mathrm{Cr}-\mathrm{Ag}$ when excited by these secondury beams was found to be governed by the foilowing laws:- $(a)$ With a given substance as radiator, its characteristic radiation is only excited by those secondary beams which are more penetrating than the tertiary radiation characteristic of the substance. (b) When the secondary beam is only just more penetrating than the tertiary the intensity of the latter is small, but as the secondary beam becomes more penetrating a very rapid increase in the intensity of the tertiary radiation to a maximum takes place. (c) As the secondary beain becomes more penetrating still, the intensity of the tertiary radiation decays as a linear function of the ionization produced in a given volume of air by the secondary beam.

(3) It bas been found that when the secondary homogeneous beams from the group of metals $\mathrm{Cr}-\mathrm{Ag}$ are absorbed by thin sheets of metals from the same group, a big increase in the absorption takes place when the secondary beams K 2 
become more penetrating than the radiation characteristic of the absorber, this increase in the absorption being intimately connected with the emission of tertiary radiation by the absorber in these circumstances (see paper on "The Absorption of X-Rays," Barkla \& Sadler, Phil. Mag. May 1909).

The fraction of this increase in the absorption of the energy of the secondary beam, which is re-emitted as tertiary radiation, is not constant, but decreases as the secondary beam becomes more penetrating, slowly at first, and then more rapidly when a very penetrating secondary beam is used.

In conclusion I wish to thank Dr. Barkla for the interest he has shown throughout this research, and especially for his kindly criticism and advice during the writing of this paper.

George Holt Physics Laboratory,

University of Liverpool, 24th March, 1909.

XII. On a Method of Determining the Sensibility of a Balance. $B y$ J. H. Poynting, Sc.II., F.R.S., and G. W. Todd, M.Sc.*

T $N$ the method, as we have arranged it, a small frame 1 (fig. 1, end view) is fixed at the centre of the beam of a 16-inch Oertling balance. This carries two $V_{s}$ about $2 \mathrm{~cm}$.

Fig. 1.

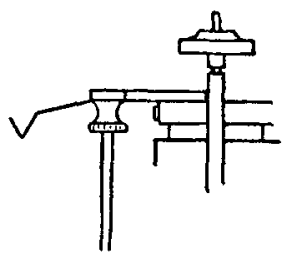

End view of $V$ frame fixed to balance-beam.

apart, and in the $V_{s}$ lies a straight wire or fibre about $3 \frac{1}{2} \mathrm{~cm}$. long, parallel to the beam and level with the central knifeedge. This wire takes the place of the ordinary rider, and

* Communicated by the Physical Society : read June 25, 1909. 